\title{
Problem-based learning in advanced photonics manufacturing: bringing real-world applications to the classroom
}

Nicholas Massa, Judith Donnelly, Gary Mullett

Nicholas M. Massa, Judith F. Donnelly, Gary J. Mullett, "Problem-based learning in advanced photonics manufacturing: bringing real-world applications to the classroom," Proc. SPIE 11143, Fifteenth Conference on Education and Training in Optics and Photonics: ETOP 2019, 111431J (2 July 2019); doi: 10.1117/12.2523803 


\title{
Problem-based learning in advanced photonics manufacturing: Bringing real-world applications into the classroom
}

\author{
Nicholas M. Massa*a Judith F. Donnelly ${ }^{\mathrm{b}}$, Gary J. Mullett ${ }^{\mathrm{a}}$ \\ ${ }^{\text {a S}}$ Pringfield Technical Community College, 1 Armory Square, Springfield, MA, USA 01102; ${ }^{\mathrm{b}} \mathrm{New}$ \\ England Board of Higher Education, 45 Temple Place, Boston, MA, USA 02111
}

\begin{abstract}
As the applications of photonics technology continue to expand into an ever-growing number of advanced manufacturing applications including laser materials processing, additive manufacturing, 3D sensing, medical devices, photonic integrated circuits and consumer products, science, technology, engineering and math (STEM) programs often struggle to prepare graduates with the critical thinking and problem solving skills needed to keep pace with this rapidly changing technology. In this paper, we describe how Springfield Technical Community College (STCC), in partnership with the Massachusetts Institute of Technology (MIT) AIM Photonics Academy, the New England Board of Higher Education (NEBHE), and the National Science Foundation Advanced Technological Education (NSF-ATE) Regional Center for Next Generation Manufacturing (RCNGM) are addressing this struggle through a three-year NSF-ATE project entitled "Problem-based Learning in Advanced Photonics Manufacturing (APM-PBL)." In this project, we are creating eight multimedia problem-based learning (PBL) "Challenges" focused on authentic real-world problems in advanced photonics manufacturing in collaboration with photonics industry and research university partners. Training in the use of these Challenges and ongoing support will be provided for 24 high school and college STEM educators from throughout New England. These PBL Challenges will be made available online at no cost to high school and college STEM educators and will add to a growing online library of 20+ PBL Challenges created in three previous NSF-ATE grants awarded to NEBHE.
\end{abstract}

Keyword: Problem-based learning, photonics, advanced manufacturing, critical thinking, optics, lasers, problemsolving.

\section{INTRODUCTION}

A recent MarketWatch report estimates the worldwide photonics market size to reach $\$ 724.22$ billion by 2021 , representing a compound annual growth rate of $8.4 \%$ from 2016 to 2021, dominated by growth in advanced manufacturing technology. ${ }^{1}$ This is especially true in the New England region. A 2015 study conducted by Deloitte Consulting for the New England Council ${ }^{2}$ revealed that the economy in the Northeast (NE) region, including New England and New York, has unique capabilities in advanced manufacturing in a broad range of industries including aerospace and defense, optics and fiber optics, lasers, medical devices and biotechnology, semiconductors and precision machining. A critical aspect of these industries is the integration of photonics technology in the manufacturing process. In another study conducted by the National Science Foundation's OPTEC Center ${ }^{3}$, industry surveys showed that the largest number of employed optics and photonics technicians are located in the West and in New England, with over $70 \%$ of employers expressing a critical need for additional optics and photonics technicians. In short, both regionally and nationally, the demand for optics and photonics technicians is growing rapidly and greatly outweighs the total number of degreed graduates of produced annually.

As the applications of photonics technology continue to expand in an ever-growing number of advanced applications including laser materials processing, additive manufacturing, 3D sensing, medical device fabrication, photonic integrated circuits and consumer products, STEM education programs often struggle to attract and graduate enough optics and photonics students with the critical thinking and problem solving skills needed to keep pace with this rapidly changing technology. This burgeoning industry demands creative, teamwork-oriented problem solvers - individuals capable of skillfully applying their knowledge of photonics in cutting-edge $21^{\text {st }}$ century manufacturing applications. One of the challenges facing educators, however, is the overall lack of engaging curriculum material focused on advanced photonics 
manufacturing applications across a broad cross section of industries that can motivate and capture student interest while at the same time develop technical content knowledge, problem-solving and critical thinking skills. In short, we need to transition from graduating "good students" to graduating "good problem-solvers."

Good problem solvers are described as those who "know what to do when you don't know what to do." A good problem solver is someone who approaches a problem in a structured and systematic way, able to analyze and properly frame the problem, identify necessary information and resources, and skillfully apply their knowledge in converging on a solution that satisfies the solution criteria. Good problem solvers are patient and methodical, carefully considering all options before moving forward toward a solution. Good problem solvers break complex problems down into smaller, more manageable steps, making reasoned decisions on how to approach each step. Good problem solvers use metacognitive strategies to manage the problem solving process by planning, monitoring, and evaluating their progress and strategies during problem solving, adjusting their approach when necessary. Unfortunately, traditional instructor-centered approaches to STEM education often do not provide adequate opportunities for students to develop the knowledge and skills necessary to solve ill-structured real-world problems. One instructional method that has been shown to be effective in facilitating the development of these strategic problem-solving skills is PBL. ${ }^{4-8}$

PBL is a learner-centered instructional method in which students learn by solving authentic real-world problems, actively and collaboratively. PBL addresses the widespread concerns of industry that graduates of STEM programs often have difficulty applying their technical knowledge in novel situations and working effectively in teams. In PBL, the instructor serves as a facilitator or consultant, guiding the students through the problem solving process and providing instruction on an "as needed" basis. Research shows that PBL results in "deep" learning rather than "surface" learning, improves critical thinking and problem-solving skills, motivation for learning, and students' ability to skillfully apply knowledge in new and novel situations - skills deemed critical for lifelong learning. ${ }^{9-13}$

In PBL, students actively participate in their own learning by solving real-world problems in which the parameters are ill-defined and ambiguous. Unlike traditional instruction in which students attend lectures, solve well-defined end-ofchapter homework problems, and engage in highly structured "cookbook" type laboratory activities, PBL is open-ended and contextualized, whereby student learning is driven by the problem itself. With PBL, students' learn the process of learning in addition to course content by engaging in a systematic and recursive process that begins by carefully defining and framing the problem, reflecting on prior knowledge to identify knowledge gaps and situational constraints, and making informed assumptions when required information is unavailable. Once the problem has been properly framed, students engage in self-directed learning to acquire the information needed to solve the problem. Once the necessary information has been gathered, a brainstorming session is conducted in which team members present and evaluate their findings and converge on a possible solution. The solution is then tested to evaluate the extent to which it addresses the criteria established in the problem analysis phase. The process is repeated if refinements or further validation are needed. This self-regulated learning process helps students acquire the metacognitive skills essential for life-long learning.

\section{PROJECT OVERVIEW}

One of the challenges of implementing PBL in photonics technology education is the lack of resources and training available to educators. To address this challenge, the APM-PBL project will build upon three prior NSF-ATE projects of NEBHE $^{14}$, collectively known as The PBL Projects (www.pblprojects.org). Since 2006, these three NEBHE projects have created over 20 online multimedia PBL instructional modules called PBL Challenges that focus on photonics technology, sustainable technology, and advanced manufacturing, available at no cost to educators. The projects also provided professional development and support to over 100 STEM educators nationwide in their use as well as peer reviewed research on the efficacy of PBL with regard to student learning outcomes and teacher adaptation strategies. Building on past success, the new APM-PBL project will:

1. Create eight new multimedia PBL Challenges focused on real-world problems in advanced photonics manufacturing

2. Provide professional development for high school, community and four-year college STEM educators across the Northeast in advanced photonics manufacturing applications, PBL pedagogy and classroom implementation strategies 
3. Develop a comprehensive recruitment strategy for increasing the pipeline of high school and community college students motivated and prepared to pursue career pathways in advanced photonics manufacturing

4. Conduct scholarly research on the efficacy of PBL with regard to improving advanced photonics manufacturing education in the Northeast.

The overarching goal of the project is to increase the pipeline of photonics technicians prepared with the knowledge and skills needed to sustain and grow the advanced photonics manufacturing industry in the Northeast through student engagement with real-world industry problems drawn from the advanced photonics manufacturing industry. Special emphasis placed on the development of PBL Challenges focused on silicon photonic integrated circuits (PICs) will support the work of the MIT's AIM Photonics Academy. ${ }^{15}$ AIM Photonics Academy is the education, workforce development, and road mapping arm of AIM Photonics ${ }^{16}$, one of 14 public-private manufacturing innovation institutes launched as part of the 2014 Revitalize American Manufacturing Innovation Act ${ }^{17}$. In addition, in an effort to increase the pipeline of students entering the field of photonics, a series of summer "Laser Camps" are planned for middle- and high school students beginning in summer 2019 to introduce students to basic optics and photonics principles concepts including holography, spectrometry, imaging, laser materials processing as well as career opportunities.

\subsection{The PBL Challenges}

The PBL Challenges are self-contained online multimedia instructional modules designed to develop students' problem solving ability and understanding of photonics, sustainable technologies, and advanced manufacturing principles concepts and applications ${ }^{18-22}$.

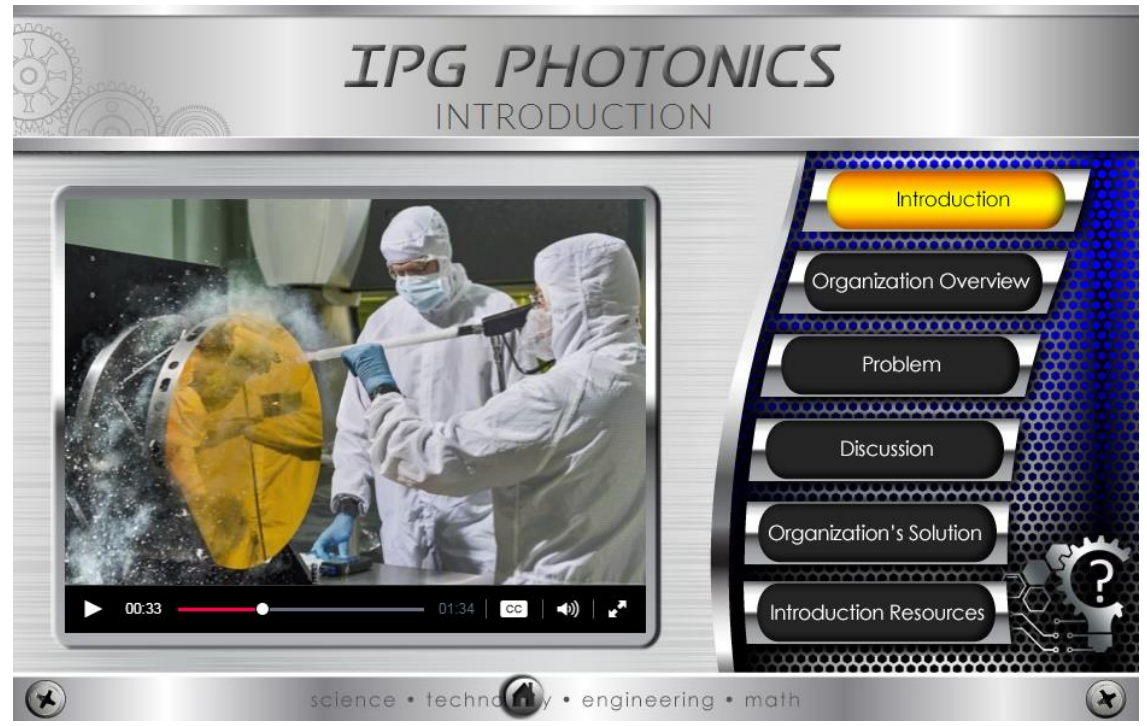

Figure 1 - PBL Challenge

The PBL Challenges provide students with authentic real-world problems presented in a multimedia format designed to emulate the real-world context in which they were encountered and solved. Each PBL Challenge contains five main sections as illustrated in figure 1.

1. Introduction - An overview of the particular photonics topic to be explored

2. Company/University Overview - An overview of the organization that solved the problem to set the context of the problem

3. Problem Statement - A re-enactment of an authentic real-world photonics problem as originally presented to the organization's technical team

4. Problem-Discussion - A re-enactment of the brainstorming session engaged in by organization's technical team

5. Organization Solution - A detailed description of the organization's solution to the problem 
The Problem Discussion and Problem Solution sections are password protected allowing instructors to control the flow of information and pace of instruction. Each of the five main sections contain additional information and resources (i.e., scripts, websites, spec sheets, etc.) designed to guide the student through the problem solving process. The PBL

Challenges are designed to be implemented with varying degree of instructor guidance ranging from highly structured (instructor led) to open-ended (instructor guided) to provide the scaffolding needed to assist students in the acquisition of the problem solving skills through a developmental continuum.

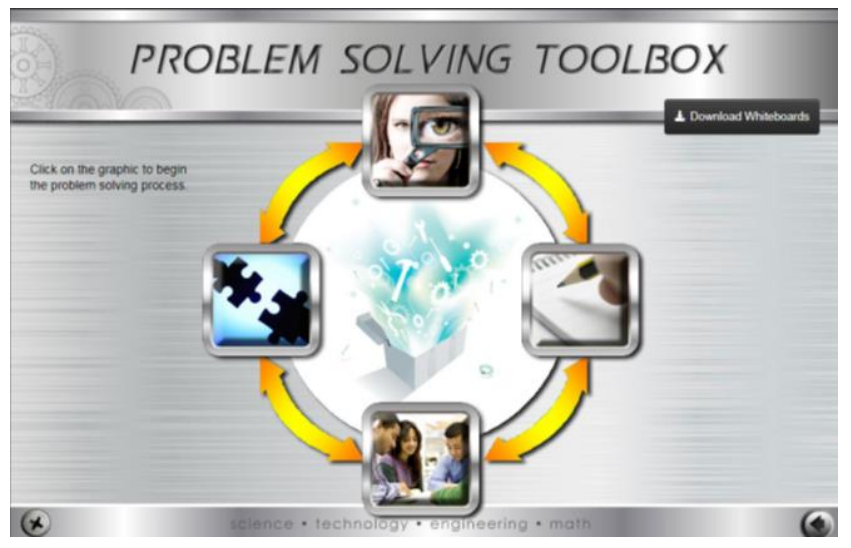

Figure 2 - The Problem Solving Toolbox
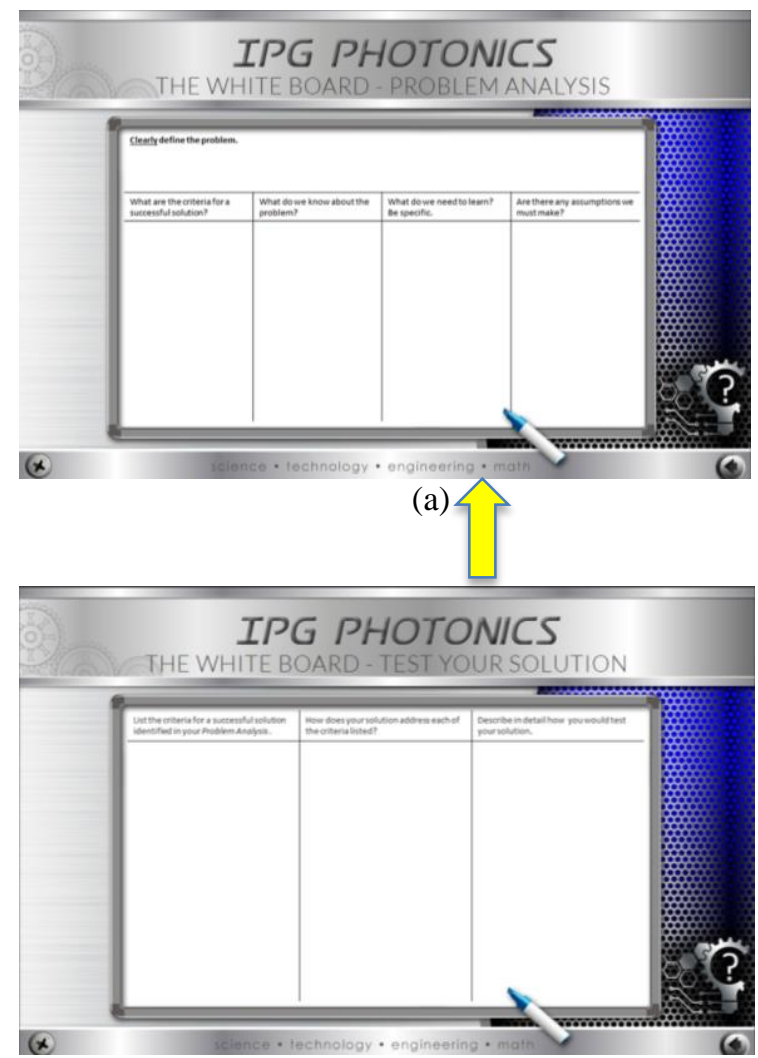

(c)

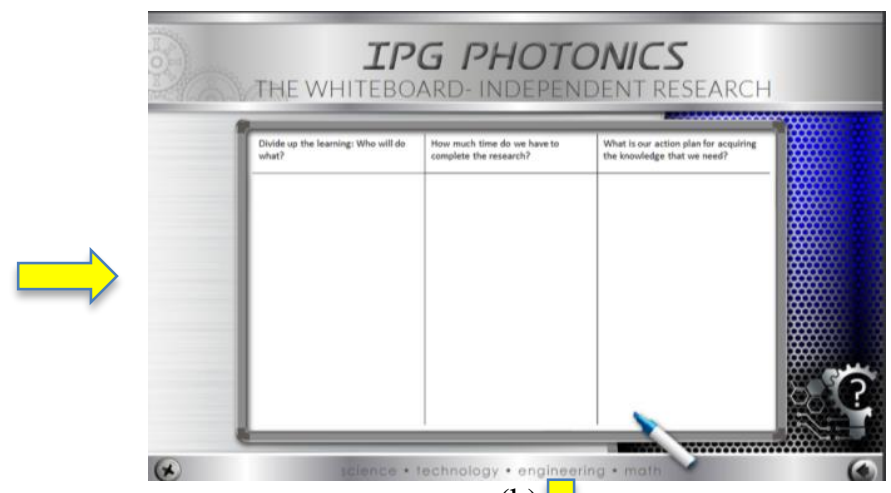

(b)
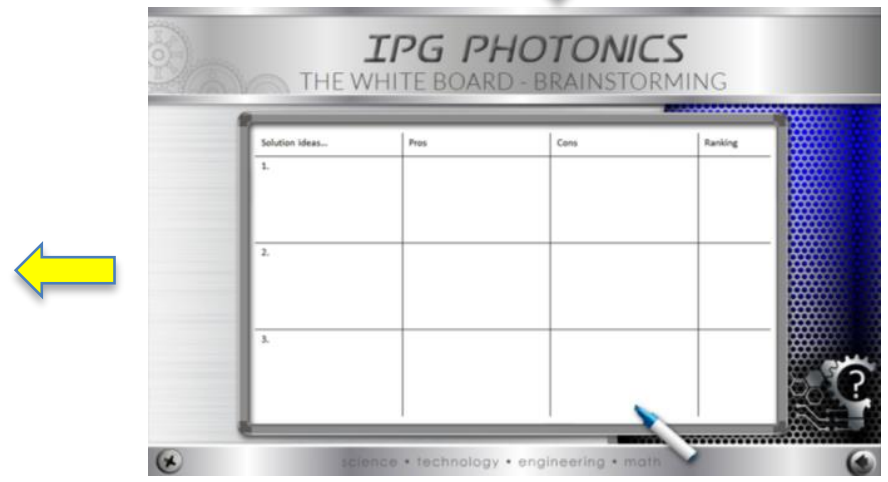

(d)

Figure 3 - The Whiteboards: (a) Problem Analysis, (2) Independent Research, (3) Brainstorming, and (4) Test Your Solution 
A unique feature of the PBL Challenges is the "Problem Solvers Toolbox." The Problem Solvers Toolbox, as illustrated in figure 2, helps students develop a systematic approach to problem solving through a feature called "The Whiteboards" that guide students through four-phase problem solving process.

The Whiteboards, shown in figure 3, help students systematically capture and document the process they used in solving the problem - their thoughts, ideas, and learning strategies during each stage of the problem solving process. The Whiteboards are a novel and effective formative assessment strategy that can be used by instructors to elucidate students' thought processes and justification for decisions made during the problem solving process.

The four Whiteboards are described below:

a) Problem Analysis - Identifying what is known, what needs to be learned, assumptions, and any problem constraints to properly frame the problem

b) Independent Research - Setting specific learning goals, identifying necessary resources, dividing team member tasks, and developing a timeline for achieving goals

c) Brainstorming - Collaboratively generating and evaluating ideas and alternative solutions best suited for addressing the task at hand

d) Test Your Solution - Developing a plan to validate the solution based on specific performance criteria

Each PBL Challenge also contains a Teacher Resource section that includes (1) a detailed technical tutorial to provide instructors with the technical background needed to understand the problem and its solution, (2) a series of assessment tools and strategies, (3) a standards alignment, (4) implementation resources, and (5) grade level adaptations (implementation case studies). The Teacher Resource page is illustrated in figure 4.

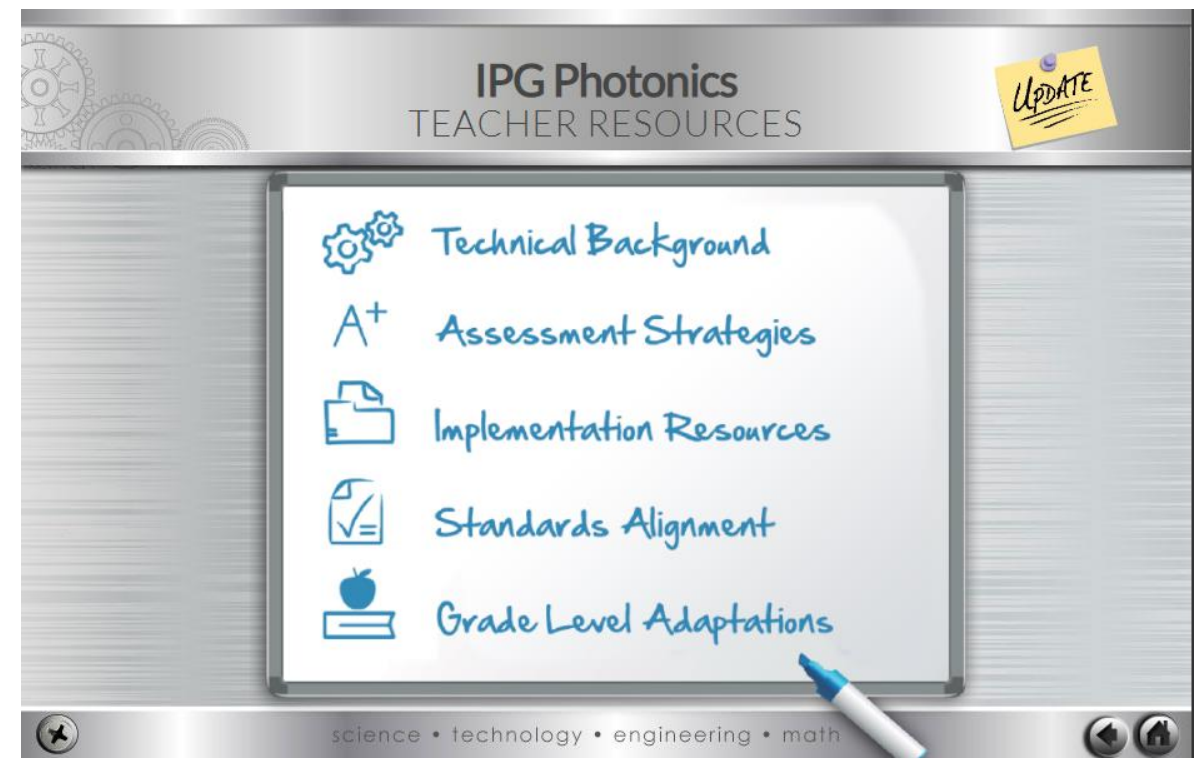

Figure 4 - Teacher Resources

\section{The APM-PBL CHALLENGES}

The APM-PBL Challenges expand the scope of the previous PBL Challenges by focusing on problems dealing with the application of photonics technology in advanced manufacturing. In creating the new APM-PBL challenges, a series of industry panel discussions with advanced photonics manufacturing companies and research universities in the Northeast was conducted to identify critical applications in which photonics technology is being used to improve manufacturing productivity and break new ground in a number of cutting edge new technologies including photonic integrated circuits, fiber lasers, additive manufacturing, optical design, 3D sensing, and many others. In the first year of the project, six 
advanced photonics manufacturing "problems" that will serve as the basis for the new PBL Challenges have been identified and are currently being developed. Discussions with photonics companies in the region to identify appropriate applications for the remaining two PBL Challenges are ongoing. The goal is to have all eight APM-PBL Challenges completed by summer 2020, at which time a series of introductory webinars followed by a week-long professional development summer institute will be conducted to train 24 high school and college STEM educators from across the New England region in advanced photonics manufacturing technology and applications as well as PBL instructional methodology. A description of the first six PBL Challenges and the companies/organizations sponsoring their development is provided below:

\subsection{Coherent-Nufern}

Problem: Active Fiber Efficiency Testing - In this problem, students teams are tasked with designing an active fiber efficiency test bench system to measure the efficiency and insertion loss of an active fiber (ytterbium doped) coil for Coherent-Nufern Corporation. In a prior set up, the company's methods for measuring active fiber efficiency were resulting in inaccurate data for the end user/customer. As a result, the company's customers had problems integrating the fiber into their systems because of inconsistencies with how fiber parameters were being measured. This PBL Challenge entails developing an improved fiber test \& measurement system and procedure that will produce more accurate and repeatable results. The prior test bench is shown in figure 5.

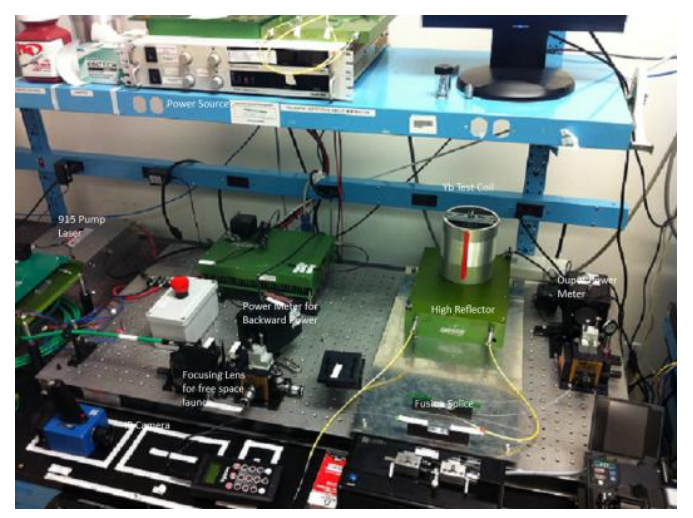

Figure 5 - Active Fiber Efficiency Bench (Photo courtesy of Richard LaCroix - Coherent-Nufern, Inc.)

\subsection{Connecticut Center for Advanced Technology (CCAT)}

Problem: Additive Manufacturing - An aerospace component manufacturer wants to know if it is feasible and economical to use additive manufacturing to create functional aerospace parts. In this problem, student teams will investigate the appropriateness of two methods of additive manufacturing: (1) flatbed powered metal sintering approach using a 2 kilowatt fiber laser, and (2) molten pool selective laser sintering approach using a 2.5 kilowatt direct diode laser. Criteria for selection includes cost/volume of powdered metal vs. traditional subtractive manufacturing, production time, accuracy/tolerance, and product performance. Figure 6 illustrates an aerospace component being created using a hybrid molten-pool selective laser sintering approach.
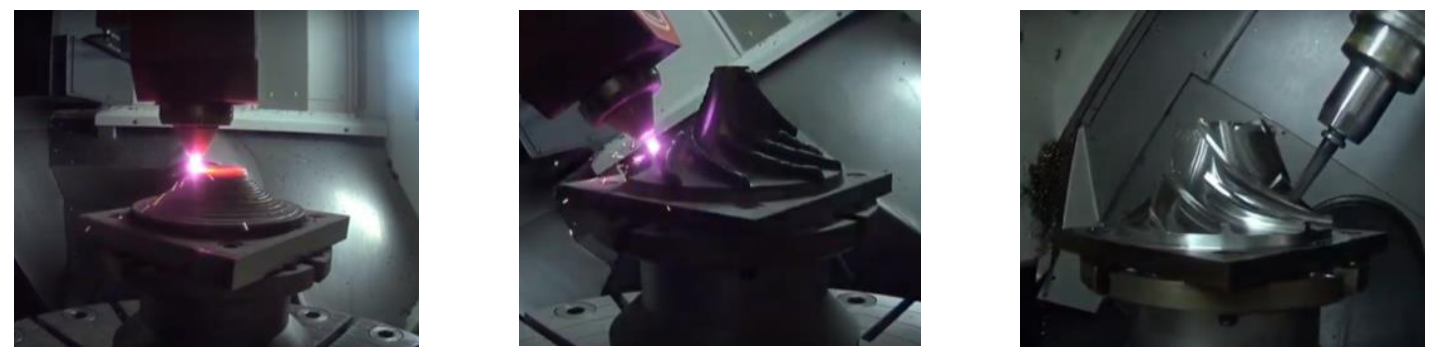

Figure 6 - 5-Axis Simultaneous 3D Additive Hybrid Manufacturing (Photos Courtesy of Jeffery Crandall - CCAT) 


\section{3}

\section{Convergent Photonics, Inc.}

Problem: Active Fiber Characterization - Convergent Photonics builds high powered fiber laser systems for the automotive industry and other industrial markets. The company purchases its active fiber (Ytterbium doped) from a number of outside vendors and needs to develop a testing protocol for measuring fiber absorption across a broad spectrum of pump laser wavelengths. With different vendors providing active fiber, the company needs to develop a robust method for characterizing each fiber in order to improve the reliability and output power stability of its industrial fiber lasers. In this problem, student teams must design an active fiber characterization test strategy that addresses accuracy and repeatability with regard to how laser light is coupled into the fiber, insertion loss measurement, spectral absorption, and the overall design/cost of the laboratory test bench.

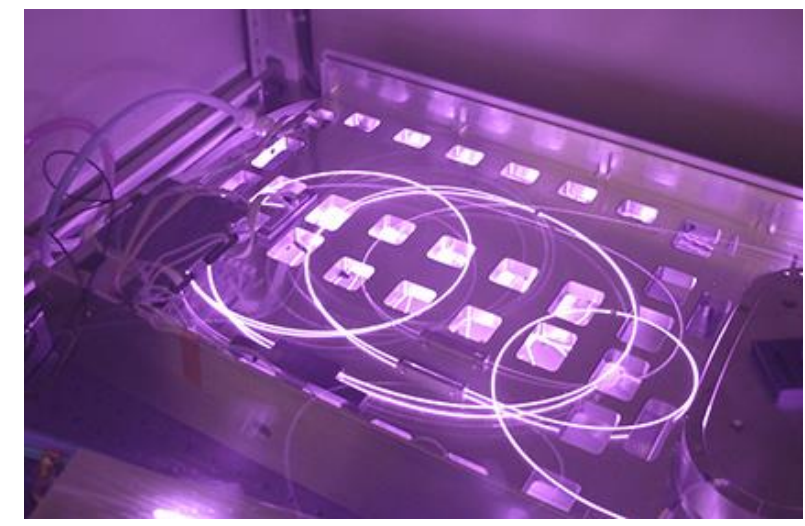

Figure 7 - Ytterbium-Doped Active Fiber (Photo courtesy of Convergent Photonics, Inc.)

\subsection{IPG Photonics, Inc.}

High Power Fiber Laser Beam Welding - In this problem, student teams are tasked with developing an optical beam delivery system for a multi-kilowatt fiber laser system. The application for this system is the laser welding of mild steel components used in industrial roof trusses. The current process for performing this application is welding all components with a MIG torch. The goal is determining how to increase cycle time and decrease the amount of spatter present in the current process. Students will need to determine the appropriate laser beam delivery optics, focused spot size, laser power, and output beam characteristics.

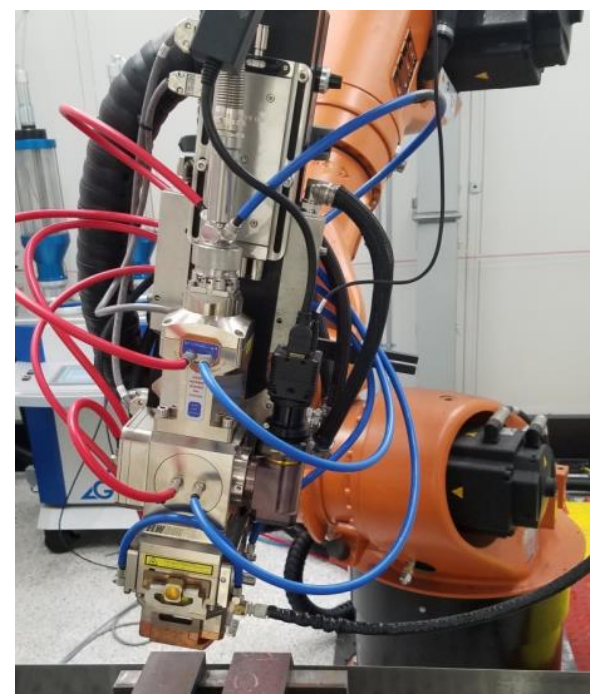

Figure 8 - IPG Fiber Laser Beam Delivery System (Photo courtesy of Joseph Roy - IPG Photonics, Inc.) 
In these two problems, student teams will use simple to use but powerful newly-developed integrated photonic device simulations to develop and optimize conceptual solutions for integrated photonic device fabrication. Figure 10 illustrates two of the simulations.

Problem 1: Methane sensing in optical waveguides - Chemical sensing along a gas pipeline is vital to the safe transportation of fuel over long distances. In order to develop these sensors, MIT has encountered and solved multiple designs and testing challenges in the research laboratory. These include creating a sealed inflow-outflow chamber for testing of integrated photonic circuits that do not harm the chip surface, as well as optimizing path length in a square centimeter of exposed circuit components (using a space-filling curve, e.g. snake bends and spirals). In this problem, student teams will examine how to effectively and efficiently introduce chemical substances to the integrated photonic waveguide sensor as well as optimize the design of the waveguide structure using software simulations. An illustration of the methane gas sensor is shown in figure 9 .

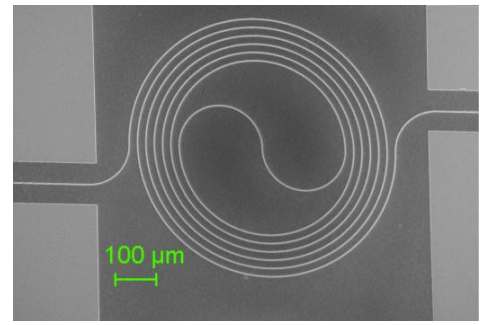

(a)

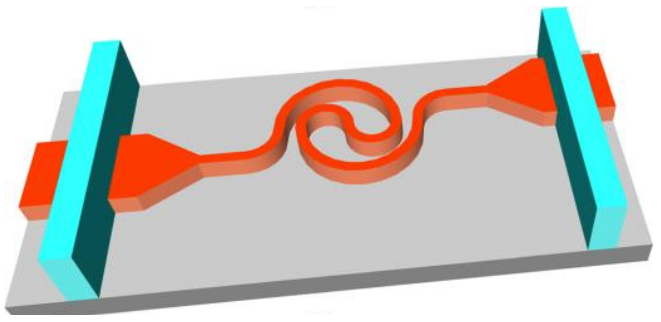

(b)

Figure 9 - Methane Gas Sensor: (a) SEM image of a $2 \mu \mathrm{m}$ wide single-mode spiral waveguide; (b) A schematic representation of the waveguide design. (Image source: "On-chip mid-infrared gas detection using chalcogenide glass waveguide," Applied Physics Letters 108, 141106 (2016); doi: 10.1063/1.494566)

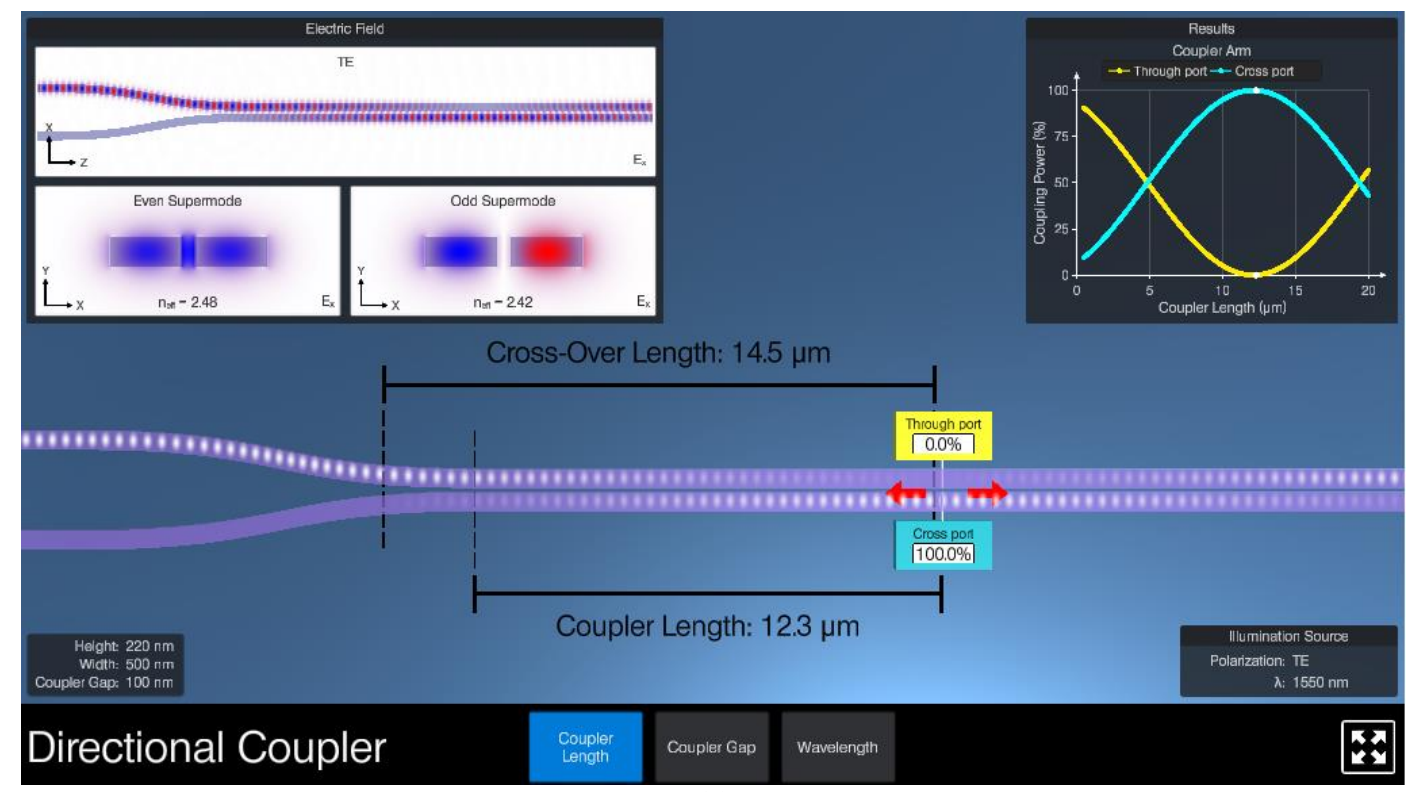

(a)

Figure 10 - Photonic Integrated Circuit Waveguide Simulations: (a) Directional Coupler, (2) Waveguide Fundamentals. (Photos courtesy of Dr. Erik Verlange - AIM Photonics Academy) 


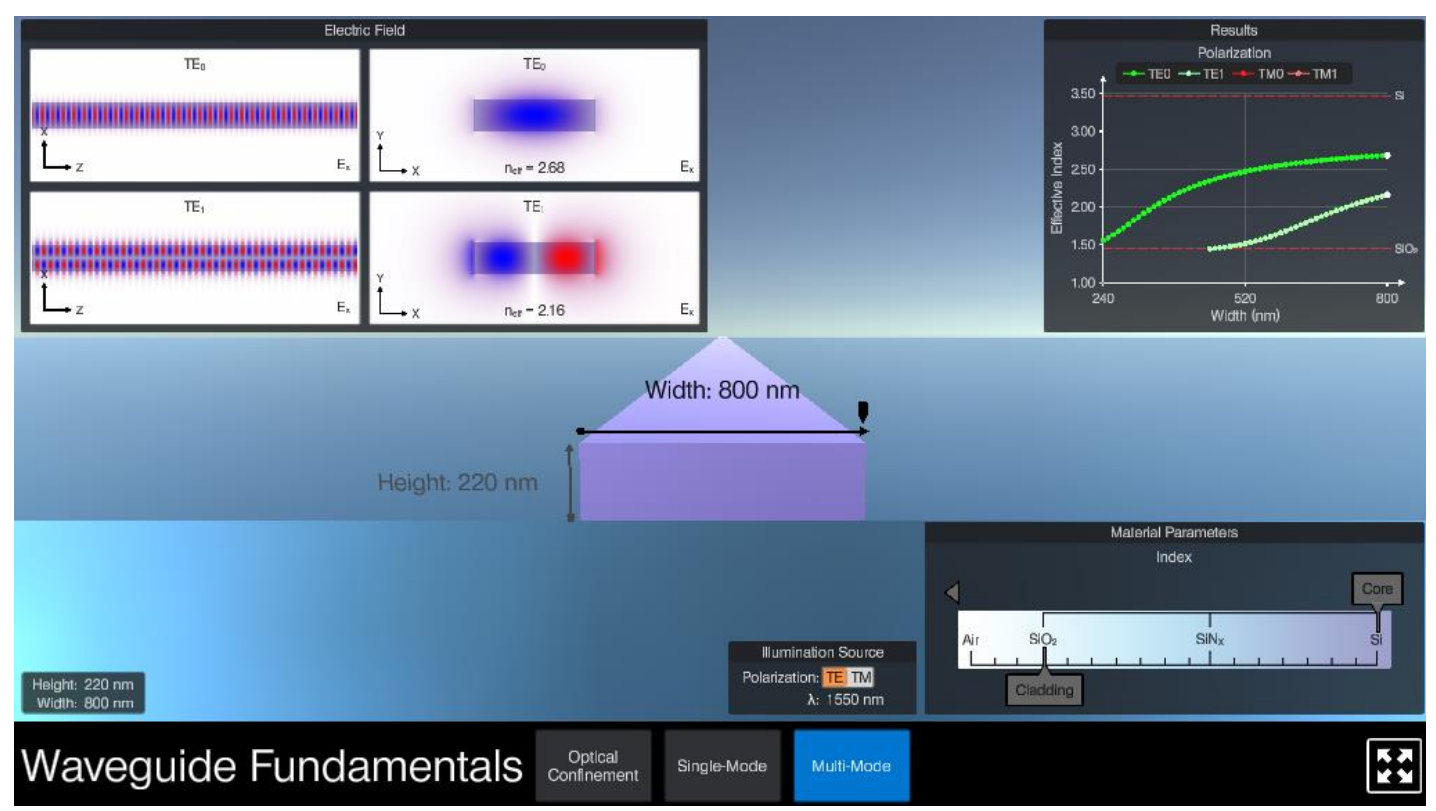

(b)

Figure 10 (continued) - Photonic Integrated Circuit Waveguide Simulations: (a) Directional Coupler, (2) Waveguide Fundamentals. (Photos courtesy of Dr. Erik Verlange - AIM Photonics Academy)

Problem 2: Tapered waveguides and micro-lensed optical fiber manufacturing for data communications - Efficiently coupling laser light from large optical fibers $(\sim 100 \mu \mathrm{m})$ into silicon photonics waveguides $(450-500 \mathrm{~nm})$ presents many design challenges, especially the need to avoid mode mismatch and coupling loss. In this problem, student teams are tasked with determining how best to use tapered waveguide structures to effectively couple light in and out of an integrated photonic device. Consideration will be given to how the solution will create additional constraints on design for testing, assembly, and packaging.

\section{CONCLUSION}

In this paper, we described how Springfield Technical Community College, in partnership with the MITAIM Photonics Academy, the New England Board of Higher Education, and the NSF-ATE Regional Center for Next Generation Manufacturing are addressing the need for photonics technicians with real world problem-solving and critical thinking skills through a three-year NSF-ATE project entitled "Problem-based Learning in Advanced Photonics Manufacturing." Eight multimedia PBL Challenges focused on authentic real-world problems in advanced photonics manufacturing are currently being developed in collaboration with photonics industry and research university partners. To date, six PBL Challenge problem scenarios have been identified and are described in this paper. Two additional problem scenarios are being investigated. Professional development in the use of these eight PBL Challenges for 24 high school and college STEM educators will be conducted through a week-long summer institute in 2020. These eight PBL Challenges, along with 20+ previously developed PBL Challenges will be available online at no cost to STEM educators by the New England Board of Higher Education at www.pblprojects.org.

\section{REFERENCES}

[1] "Worldwide Photonics Market Growth of 8.4\% CAGR to 2021 Dominated by Manufacturing Technology," http://www.marketwatch.com/story/worldwide-photonics-market-growth-of-84-cagr-to-2021- dominated-bymanufacturing-technology-2016-09-26-420329, (Sept 26, 2016)

[2] New England Council and Deloitte Consulting, "Advanced to Advantageous: The Case for New England's Manufacturing Revolution," April 2015. Available at http://newenglandcouncil.com/assets/Advanced-toAdvantageous_FINAL-Report_04-08-2015.pdfmanufacturing-technology-2016-09-26-420329 
[3] Hull ,Illich and Dossey, Estimation of National and Regional Industry Demand for Photonics Workers in the United States Education and Training in Optics and Photonics: ETOP 2015, edited by Eric Cormier, Laurent Sarger Proc. of SPIE Vol. 9793, 97932C

[4] Johnson, K., Herr, T., and Kysh, J. (2004). Crossing the river with dogs. California: Key College Publishing.

[5] Schoenfeld, A. H. (1992). Learning to think mathematically: problem solving, metacognition, and sense making in mathematics. In D. A. Grouws (Ed.), Handbook of research on mathematics teaching and learning: A project of the National Council of Teachers of Mathematics. New York: MacMillan.

[6] Krulik, S. \& Rudnick, J. A. (1980). Problem solving: A handbook for teachers. Boston: Allyn and Bacon, Inc.

[7] Polya, G. (1957). How to Solve It: A New Aspect of Mathematical Method, Second Edition. Princeton, NJ. Princeton University Press.

[8] Lochhead, Jack, and Arthur Whimbey. (1980). Problem Solving and Comprehension. Philadelphia: The Franklin Institute Press.

[9] Savery, J. R., \& Duffey, T. M. (1996). Problem based learning: An instructional model and its constructivist framework. In B. G. Wilson (Ed.), Constructivist learning environments: Case studies in instructional design. Englewood Cliffs, NJ: Educational Technology Publications.

[10] Barrow, H.S. (1986). A Taxonomy of Problem Based Learning Methods. Medical Education 20: 481-486.

[11] Hmelo-Silver, C. E. (2004, September). Problem-Based Learning: What and How Do Students Learn? Educational Psychology Review 16 (3).

[12] McKenna, A., Walsh, J., Parsek, M. and Birol, G. (2002). Assessing Challenge Based Instruction in Biomedical Engineering. Proceedings of the American Society for Engineering Education (CD-ROM DEStech Publications) Session 2218.

[13]Zubaidah, S. (2005). Problem-Based Learning: Literature Review. Singapore Nursing Journal, 32 (4), OctoberDecember: 50-54.

[14] http://www.photonprojects.org

[15] https://aimphotonics.academy/

[16] https://aimphotonics.com

[17] H.R. 2996 - 113th Congress: Revitalize American Manufacturing and Innovation Act of 2014." www.GovTrack.us. 2013. April 18, 2019 https://www.govtrack.us/congress/bills/113/hr2996

[18] Massa, N.M., Audet, R., Donnelly, J., Hanes, F., Kehrhahn, M., \& Bell, A., "Photon PBL: Problem- Based Learning in Photonics Technology Education," Paper presented at the Photonics North: Education and Training in Optics and Photonics (ETOP) Annual Conference, June 2007, Ottawa, Canada

[19] Massa, N.M., Donnelly, J. (2015, July). "The PBL Projects: Where we've been and where we are going", Invited paper presented at 13th Education and Training in Optics and Photonics (ETOP) Conference, Bordeaux, France.

[20] Massa, N. M., Donnelly, J., Hanes, F. (2013, July). Student Reactions to Problem-Based Learning in Photonics Technician Education. Paper presented at the Education and Training in Optics and Photonics (ETOP) Conference, Porto, Portugal.

[21] Massa, N. M., Dischino, M., Donnelly, J., Hanes, F. (2012, June). Problem-Based Learning in a Pre-Service Technology and Engineering Education Course. Paper presented at the American Society of Engineering Education (ASEE) Annual Conference, San Antonio, TX.

[22] Massa, N. M., Dischino, M., Donnelly, J., Hanes, F. (2011, June). Creating Real-World Problem-Based Learning Challenges in Sustainable Technologies to Increase the STEM Pipeline. Paper presented at the American Society of Engineering Education (ASEE) Annual Conference, Vancouver, BC. 